\title{
Interações, espaços e ambientes utilizados por entendidas belorizontinas: um caminho velado
}

\author{
Janice Aparecida de Souza ${ }^{1}$ \\ Alessandra Sampaio Chacham ${ }^{2}$
}

\begin{abstract}
Resumo: Este artigo aborda a invisibilidade da homossexualidade feminina a partir da análise da experiência de uma "Confraria" de Lésbicas mineiras nascidas na década de 1950. O objetivo é refletir sobre os usos que faziam dos espaços e sobre as interações possíveis à época. Se é a partir dos processos de interação social que o sentido e o significado nas relações emergem, a forma pela qual a cidade acolhe ou ignora e invisibiliza determinados sujeitos impacta suas vidas. O modo pelo qual elas se apropriaram dos espaços disponíveis na cidade de Belo Horizonte e a criação de outros espaços mais reservados foram fundamentais para a criação de longevos vínculos de amizade e convivência. Tais vínculos parecem ter colaborado para uma rede de apoio mais estruturada na velhice formada por relações de afeto, amizade e solidariedade
\end{abstract}

Palavras-chave: Cidade - Lésbicas - Envelhecimento - Invisibilidade - Redes de Solidariedade

\section{Interactions, spaces and places used by "entendidas" belorizontinas: a obfuscated path}

\begin{abstract}
This article discusses the invisibility of female homosexuality based on the experience of a "sisterhood" of lesbians from Minas Gerais born in the 1950s. The objective is to reflect on the uses they made of spaces and the possible interactions at the time. If it is from the processes of social interaction that sense and meaning in relationships emerge, the way in which the city welcomes or ignores and makes certain subjects invisible impacts their lives. The ways in which they appropriated the spaces available in the city of Belo Horizonte and the creation of other more reserved spaces were fundamental for the creation of long-lasting bonds of friendship and coexistence. Such bonds seem to have contributed to a more structured support network in old age, forged in relationships of affection, friendship and solidarity.
\end{abstract}

Keywords: City - Lesbians - Aging - Invisibility - Support Networks

\footnotetext{
${ }^{1}$ Doutoranda do Programa de Pós-Graduação em Ciências Sociais - PUC Minas. Professora concursada na Faculdade de Educação da Universidade do Estado de Minas Gerais (UEMG). Foi Superintendente de Políticas de Promoção de Direitos e Cidadania, Coordenadora da Casa de Direitos Humanos e Diretora de Orientação ao Trabalho no Governo do Estado de Minas Gerais. Contato: Janice.souza@uemg.br

2 Alessandra Sampaio Chacham. Professora da Pontifícia Universidade Católica de Minas Gerais. Doutorado em Demografia pela Universidade Federal de Minas Gerais, Brasil (1999).
} 


\title{
Sobre elas e suas interações
}

\begin{abstract}
"Éramos tratadas como doentes e pervertidas, párias da sociedade. Um horror! A sociedade hipócrita sempre nos tratou com nojo e desrespeito. Avançamos muito nessa questão, mas ainda estamos longe do ideal”.
\end{abstract}

Cachinho, 64 anos $-\mathrm{BH}$

A epígrafe com a qual iniciamos este texto é de uma mulher homossexual mineira que viveu intensamente os processos de estigmatização que marcaram a sua geração na cidade de Belo Horizonte. Ela faz parte de uma "Confraria de Entendidas"3 que juntas construíram estratégias para viver, à revelia do modelo patriarcal, sexista e heteronormativo imposto, a negada sexualidade que desejavam. Nomeavam-se Entendidas, como outras contemporâneas! Desta forma identificavam a orientação sexual, sem, entretanto, serem expostas abertamente aos preconceitos vividos, noutros tempos ainda mais limitadores.

As "Confreiras", cujos vínculos entre algumas chega a remontar à adolescência, tiveram os seus primeiros contatos por meio da prática de esportes: futebol, handball e vôlei. Chegaram a ser vitoriosas em um campeonato de futebol acontecido em Belo Horizonte. Nas palavras de uma delas: "o handebol e, principalmente o futebol, foi o que nos reuniu, primeiro jogando, depois, quando acabaram os joelhos e tornozelos, como torcedoras" (Saião, 64 anos). À medida que foram amadurecendo passaram a se encontrar também em bares, boates, casas e sítios alugados e nas festas ${ }^{4}$ que organizavam, exclusivamente para lésbicas.

Envelheceram mantendo os vínculos tanto presencialmente quanto via Facebook ou nos diversos grupos ${ }^{5}$ de whatsApp que as congregam, como é o caso do Vila das Entendidas (21 mulheres), que a princípio me parece ter um perfil mais conservador; o Vizinhas para sempre (10 mulheres), grupo composto por cinco casais que moram em um condomínio situado em Nova Lima - MG; o Polêmico, que surgiu com o objetivo de ser um grupo sem censura de temas; o Mineirinho (22 mulheres e 1 gay $\left.^{6}\right)$, composto exclusivamente por cruzeirenses; o Camisa (24 mulheres), formado por atleticanas; e o FroGames ${ }^{7}$ (36 mulheres) composto pelas amantes do futebol. Traço este breve relato sobre os grupos com o fito de apresentar, ainda que de forma incipiente um pouco da organização e dos interesses delas.

\footnotetext{
${ }^{3}$ Utilizarei o termo Confraria para identificar, de forma ampla, o grupo de mulheres que pesquiso, aproveitando um termo usado por elas. Contudo a forma pela qual elas se identificam varia a depender da época, do evento ou do propósito que têm em pauta.

${ }^{4}$ Uma dessas festas, o Brega-Fest, virou um festival, ocasião na qual vestiam um traje barango e realizavam um concurso de trajes, músicas e performances, também barangas, as melhores eram premiadas. Aconteceu entre os anos 1977 e 1988, em espaços alugados, as festas eram fartamente regadas a comes, bebes e muita dança. Os nomes dos grupos foram alterados para manter o anonimato.

${ }^{5}$ Os nomes dos grupos foram alterados para manter o anonimato.

${ }^{6}$ Curiosa a presença desse único elemento masculino. Eu o apresentei ao grupo, foi meu colega no curso de História, dividíamos apartamento à época. Uma amizade que parecia ser para sempre, mas que sucumbiu durante os debates para as eleições presidenciais de 2018, pena.

${ }^{7}$ O nome original do grupo é outro e foi destacado em dois programas da Rádio Itatiaia em 2019. Contudo, buscando preservar o anonimato das integrantes, neste artigo virou FroGames. Na explicação de uma das Entendidas: frog é sapo em inglês e games, jogos.
} 
De acordo com Didier Eribon ${ }^{8}$ os amigos encontrados nos lugares gays substituem as relações familiares, ou mais ou menos deixadas de lado, assim como as relações no lugar de trabalho, tão difíceis de estabelecer e serem mantidas para um gay ou uma lésbica, sobretudo quando procuram esconder o que são. De acordo com Moore ${ }^{9}$ o problema de como os indivíduos levam vidas coletivas surge e ressurge como uma das problemáticas mais urgentes para a ciência social contemporânea.

Se os amigos e a forma pelas quais os indivíduos levam vidas coletivas são elementos importantes no entendimento dos autores citados, ambos se mostram igualmente relevantes no caso das Confreiras. As festivas jovens lésbicas de outrora seguem celebrando a vida e os encontros. Chegada a aposentadoria para umas tantas, criaram em 2015 o Breja da SAPiência ${ }^{10}$, evento semestral no qual é concedido o título e um crachá-medalha do mérito Vagaba $^{11}$ às recém aposentadas. Encontros nos quais sempre me faço presente. Tais encontros acontecem em bares frequentados majoritariamente por heterossexuais e neles não há qualquer manifestação explícita de afeto que revele a formação de casais entre elas. A opção por uma trajetória de vida reservada não as favoreceu no sentido de se assumirem publicamente, muito menos na família ou nos ambientes de trabalho, núcleos particularmente difíceis. No entanto, como a maioria dessas senhoras já se aposentaram, o local de trabalho deixou de ser uma questão. Quanto ao núcleo familiar de origem, alguns casais incorporaram suas parceiras nele, contudo, a manifestação de intimidade é comedida. É comum cuidarem dos pais e mães envelhecidos ou doentes juntas. Porém, a dificuldade de se exporem acompanha essas mulheres ainda em dias atuais.

A militância pelo reconhecimento de direitos sociais não fez parte da vida dessas mineiras mais maduras, mas é possível inferir a contribuição dada por elas por meio das estratégias adotadas para se relacionar, viver e amar! Em dias atuais presenciamos a relativização do preconceito pautado na superação do entendimento de que as pessoas fazem uma opção sexual, afinal, trata-se de orientação sexual. Se opção houvesse, a heterossexualidade seria a escolha mais óbvia e fácil. Tais entendimentos podem ter colaborado para o reconhecimento de muitos dos direitos alcançados atualmente. Considero importante destacar o possível legado das mais velhas às mais jovens, as quais, efetivamente militando ou se expondo, de forma física ou pelas redes sociais e virtuais, têm tentado tornar a cena de duas mulheres trocando afeto em público, no mínimo, digna de respeito.

Interessada em conhecer o universo das Entendidas, venho me dedicando à pesquisá-las. Tive meus primeiros contatos com elas nos anos 1990, ocasião em que uma amiga da faculdade começou a namorar uma mulher que fazia parte de um grupo grande e fechado de lésbicas. Algum tempo depois, em 1996, rompi uma relação heterossexual e estável para ter um caso com uma delas. Embora tenha sido uma relação séria, com endereço único e relativamente longa para os meus trinta e poucos anos, era assim que as Entendidas apresentavam suas namoradas: caso! Essa relação me inseriu em um universo restrito e completamente novo para mim. Desde então venho acumulando vivências e escutando as

\footnotetext{
${ }^{8}$ ERIBON, Reflexões sobre a questão gay, p.51.

${ }^{9}$ MOORE, Fantasias de poder e fantasias de identidade: gênero, raça e violência, p.15.

${ }^{10} \mathrm{O}$ nome Breja da SAPiência traz em si um mix de inspiração. O termo Breja, apelido para cerveja em Belo Horizonte, remete ao feminino de brejo, local habitado por sapos e sapas, este último apelido comum dado às lésbicas. Remete ainda à desejada sapiência que poderia vir junto com o envelhecimento.

11 Vagaba é uma gíria comum, abreviação de vagabunda, mulher vadia, que não presta. De acordo com as Entendidas foi escolhido por sinalizar a vagabundagem que, para elas, viria junto com a aposentadoria.
} 
histórias dessas mulheres ao longo dos mais de vinte e cinco anos de convívio. No mestrado pesquisei "Estratégias de Escolarização de Homossexuais com Sucesso Acadêmico"12 e em uma das etapas da coleta de dados apliquei cem questionários como etapa exploratória nessa confraria de lésbicas. Entretanto o material foi subaproveitado até que me dei conta de seu potencial para aprofundamento e conhecimento de um universo ainda a ser explorado e desvelado.

Se é comum que homossexuais dos dois sexos optem por uma vida anônima como estratégia de proteção, no caso das mulheres parece haver uma existência quase negada e isso se torna ainda mais contundente se pensarmos nas gerações mais antigas.

Onde escondem-se e esconderam-se as lésbicas? Em que nicho de obscuridade e silêncio se pode encontrá-las? Não se fala delas por que não existiram? Ou sua existência representa a desestabilização e o caos na ordem 'natural' e 'divina' da heterossexualidade dominada pelo masculino? ${ }^{13}$

Em uma breve incursão pelo vasto banco de teses e dissertações da Capes pode-se constatar o quão restritas e incipientes são as pesquisas sobre o universo homossexual feminino. Entre teses e dissertações, com a palavra gay, localizei 1.358 trabalhos, com a palavra lésbica 124. Ao que tudo indica é um campo ainda pouco explorado - principalmente se comparado ao universo homossexual masculino. ${ }^{14}$ Há ainda muitas histórias a serem escritas e contadas. Até então, no campo feminino, isto se deu à "boca miúda".

Pensar o lugar marginal ocupado pelas mulheres e, principalmente pelas lésbicas, talvez ajude a compreender o motivo da invisibilidade delas. Em algum lugar do passado moram histórias, resistências, memórias. Repousam ainda sonhos, dores e lutas. Embora a afirmação possa parecer - e é -, abrangente demais, ater-me-ei em abrir uma janela da qual possamos mirar, a partir de uma confraria formada por mulheres lésbicas, um universo mais amplo e invisibilizado.

\section{Sobre a cidade e seus acolhimentos - ou não}

A cidade é um estado de espírito, um corpo de costumes e tradições, está envolvida nos processos vitais das pessoas que a compõem e devem ser estudadas não apenas em seu próprio benefício, mas pelo que nos podem revelar do comportamento humano e da natureza humana em geral, segundo Park. ${ }^{15}$ Contudo, a possibilidade de fruição das cidades, suas ruas e equipamentos, se apresenta como possibilidades distintas a distintos sujeitos. No caso de heterossexuais é uma, no caso de homossexuais outra. A esses últimos coube pensar alternativas, criar soluções e outros espaços para se relacionarem.

\footnotetext{
${ }^{12}$ Cf. DE SOUZA, Estratégias de Escolarização de Homossexuais com Sucesso Acadêmico.

13 NAVARRO-SWAIN, O que é lesbianismo, p. 13.

${ }^{14}$ Esta informação precisa levar em conta a onda de pesquisas realizadas devido ao advento da AIDs no Brasil e a instabilidade do site que apresenta, por vezes números distintos. Contudo, mesmo eliminando esta peculiaridade, há muito mais estudos sobre as homossexualidades masculinas. Fonte https://catalogodeteses.capes.gov.br/catalogo-teses/\#!/. Acesso em 14/04/2020.

15 PARK, A cidade: sugestões para investigação do comportamento bumano no meio urbano, p. 26.
} 
Pessoas de status e necessidades homogêneos, consciente ou inconscientemente, se dirigem ou são forçadas a se dirigirem para determinadas áreas, na medida em que suas necessidades e modos de vida são incompatíveis uns com os outros e na medida em que sejam antagônicos. ${ }^{16}$ Dadas as contingências impostas aos homossexuais, a busca por alternativas para conhecerem outros, com eles se relacionar me soa imperativa, dessas "coisas que só o coração pode entender, fundamental é mesmo o amor, é impossível ser feliz sozinho" nas palavras daquele que é conhecido como gênio, o Tom Jobim.

Assim fizeram os homossexuais, criaram os espaços onde poderiam "ser felizes". No caso das lésbicas, data do início dos anos 1970 o registro dos primeiros bares e boates voltados para elas na capital mineira. Nesses espaços tinham liberdade para afirmar suas identidades, se assumirem, fazerem amizades e se relacionar afetivamente longe do fardo e da culpa impostos pelos olhares da tradicional família mineira.

A cena lésbica noturna de Belo Horizonte foi capitaneada pelo trio Norma Sueli, Mani e Mariinha. Foram pioneiras por terem aberto os primeiros bares e boates na capital mineira para o público homossexual feminino. Entretanto, para além desses espaços foram criados outros mais reservados. Era comum às lésbicas que viviam em Belo Horizonte várias vieram do interior do Estado - fazerem uso também de casas ou sítios alugados por temporadas, para viverem livremente suas experiências afetivas e sexuais. Nesses locais foram criadas, além da oportunidade de se relacionarem com outras mulheres, duradouras relações de amizade e afeto.

No caso de lésbicas atualmente idosas, a vida em gueto adotada por muitas, como é o caso da Confraria à qual venho estudando, parece relacionar-se tanto às contingências sociais quanto a uma estratégia deliberada de isolamento em busca de proteção.

Para Pierre Bourdieu" ${ }^{17}$, as "lésbicas são duplamente dominadas, mesmo dentro de um movimento que comporta $90 \%$ de gays e 10\% de lésbicas, uma vez que ainda é marcado por uma forte tradição masculinista". Ainda que o livro - A Dominação Masculina - tenha sido publicado nos anos 1998, na hierarquia social a diferença entre feminino e masculino persistem.

A título de exemplo, quanto à forma distinta que lésbicas e gays ocupam as cidades, encontramos a dissertação de mestrado de Teixeira ${ }^{18}$, Territórios homoeróticos em Belo Horizonte: um estudo sobre as interações sociais nos espaços urbanos. O estudo constatou que as "interações nos lugares de 'pegação' tiveram como desdobramentos a criação de marcas e vínculos necessários ao processo de construção das identidades homoeróticas dos entrevistados". Afirma o autor "não ter encontrado registros, por meio da pesquisa bibliográfica e da pesquisa de campo, sobre a existência de espaços específicos, na cidade de Belo Horizonte, que propiciassem encontros fortuitos entre mulheres, nos mesmos parâmetros que os masculinos".

Sigo atenta às pesquisas feitas com lésbicas mais velhas ${ }^{19}$, mas a busca tem se mostrado bastante desafiadora. Um estudo parecido com o apresentado neste atigo foi realizado pioneiramente por Carmen Dora Guimarães no final dos anos 1970, sob orientação

\footnotetext{
${ }^{16}$ WIRTH, O urbanismo como modo de vida, p.103.

17 BOURDIEU, A dominação masculina, p.148.

${ }_{18}$ TEIXEIRA, Territórios homoeróticos em Belo Horizonte: um estudo sobre interações sociais nos espaços urbanos, p. 13.

19 Até o momento localizei um artigo: Envelhecimento, Trajetórias e Homossexualidade Feminina de Andrea Moraes Alves. Disponível em https://www.scielo.br/pdf/ha/v16n34/10.pdf. Acesso em 24/05/2020.
} 
de Gilberto Velho. Contudo a dissertação de mestrado - O Homossexual visto por entendidos - é uma pesquisa exploratória sobre o universo homossexual masculino - jovem - na cidade do Rio de Janeiro. A maioria dos entrevistados era oriunda de Minas Gerais, rapazes que buscavam na cidade carioca uma vida com mais liberdade, para além das montanhas e distante da tradicional família mineira.

Para uma aproximação do universo homossexual de mulheres mineiras mais velhas ${ }^{20}$ tomo a pessoa, objeto de estudo do antropólogo social, e suas complexas relações sociais, como fio condutor. A antropologia, mais do que uma disciplina voltada para o estudo dos povos primitivos é, como afirma Merleau-Ponty ${ }^{21}$, "a maneira de pensar quando o objeto é 'outro' e que exige nossa própria transformação. Assim, também viramos etnólogos de nossa própria sociedade, se tomarmos distância com relação a ela".

Sob as lentes de uma estrutura patriarcal, sexista e heteronormativa, as relações sociais para aqueles que fogem à norma são fortemente marcadas por tensões, conflitos e contradições. É possível elencar seus desdobramentos sobre as vidas de quaisquer sujeitos, em uma sociedade na qual as práticas afetivas são heterocentradas e hierarquizantes, os desdobramentos transitam da invisibilidade à violência, como é possível comprovar nos mais variados meios de comunicação. Cenário favorável à opção por uma vida dentro do armário como estratégia de proteção.

Em dias atuais "as reformulações teóricas aceitas como consenso não mais admitem um tratamento distorcido e/ou preconceituoso com base nas orientações afetivo-sexuais em face das categorias identitárias divergentes dos padrões estanques da lógica binária de gênero". ${ }^{22}$ Ao contrário do que ocorre com as lésbicas mais jovens, as mais velhas viveram na invisibilidade, que, nas palavras da advogada e desembargadora Maria Berenice Dias ${ }^{23}$, "é a forma mais cruel de gerar injustiças".

As relações vividas em uma sociedade heteronormativa, patriarcal e sexista passam pelo controle dos corpos e da sexualidade. Em tais sociedades os papéis definidos como "naturais" e os comportamentos tidos como "adequados" transformam mulheres que amam mulheres em seres invisíveis.

Navarro-Swain ${ }^{24}$ traz alguns questionamentos nesse sentido: onde se escondem e se esconderam as lésbicas? Em que nicho de obscuridade e silêncio se pode encontrá-las? Não se fala delas por que não existiram? Ou sua existência representa a desestabilização e o caos na ordem "natural" da heterossexualidade dominada pelo masculino?

A vida no anonimato protege homossexuais das violências às quais estão expostos e permite a eles escapar ao controle social. Para Wirth ${ }^{25}$, a reserva, a indiferença e o ar blasé que os habitantes da cidade manifestam em suas relações podem ser encarados como instrumentos para se imunizarem contra exigências pessoais e expectativas alheias. $\mathrm{O}$ superficialismo, o anonimato e o caráter transitório das relações urbano-sociais explicam, também, a sofisticação e a racionalidade geralmente atribuídas ao habitante da cidade. Embora o indivíduo ganhe, por um lado, certo grau de emancipação ou liberdade de

\footnotetext{
20 Parto de mulheres nascidas por volta da década de 1950, algumas muito próximas têm "virado estrelas", deixado saudades e levado com elas muitas histórias ainda por contar.

${ }^{21}$ MERLEAU-PONTY, “De Mauss à Claude Lévi-Strauss”, pp. 199-200.

22 JÚNIOR, Homofobia e Violência Doméstica, p. 495.

${ }^{23}$ DIAS, Rumo a um novo direito, p. 263.

${ }^{24}$ NAVARRO-SWAIN, O que é lesbianismo, p. 13.

25 WIRTH, O urbanismo como modo de vida, p. 101.
} 
controles pessoais e emocionais de grupos íntimos, perde, por outro lado, a espontânea autoexpressão, a moral, e o senso de participação, implícitos na vida numa sociedade integrada.

De acordo com Morrow \& Messinger $^{26}$, com a pressão para se conformar à norma heterossexual, o conflito entre desejos, comportamentos e identidades, pode levar os indivíduos a experimentar isolamento, baixa autoestima, depressão e raiva. Neste sentido, foi no vasto campo que a antropologia social urbana oferece que encontrei inspiração para buscar compreender como algumas associações entre seres humanos criam fenômenos sociais decorrentes da estrutura social pela qual estão unidos. De acordo com Benedict (1968), a antropologia deveria sempre estudar a "smallness" - sociedades de pequena escala, ou seja, pequenos grupos no interior de sociedades mais amplas, e assim o faço.

Parto de um pequeno grupo de lésbicas para tentar entender, de dentro dele, como os processos de estigmatização e invisibilidade social se espraiam e impactam vidas. Atenta ao necessário distanciamento quando o objeto de pesquisa nos é familiar e próximo - mulher lésbica estudando mulheres lésbicas - reconheço a importância do acúmulo que a convivência com elas e com "seus" espaços me proporcionou. "Olhar de perto e de dentro", mas respeitando os arranjos por elas feitos para conviver e amar; para captar as formas por meio das quais elas utilizaram os equipamentos de que a cidade dispunha; como transitaram por ela, usufruíram de seus serviços e estabeleceram seus encontros e trocas nas mais diferentes esferas, religiosidade, trabalho, lazer, cultura, participação política ou associativa.

Gilberto Velho ${ }^{27}$ destaca que o familiar, com todas as necessárias relativizações, é cada vez mais objeto relevante de investigação para uma antropologia preocupada em perceber a mudança social não apenas no nível das grandes transformações históricas, mas também como resultado acumulado e progressivo de decisões e interações cotidianas.

No artigo Urbanidades Invisíveis, Carlos Fortuna ${ }^{28}$ aponta a necessidade de se trazer alguma subterraneidade urbana até o plano da visibilidade. O autor, ao citar Aubert e Haroche, chama a atenção para o fato de que a invisibilização pode ser intencional. Afinal, todas as pesquisas de opinião feitas junto aos homossexuais (dos dois sexos) atestam que a experiência de insulto (sem falar até de agressão física) é um dos traços mais comum de suas existências. Em graus diversos, é claro, conforme os países e, no seio de um mesmo país, conforme o lugar onde vivem e no meio social em que evoluem. ${ }^{29}$

Neste ponto acho oportuno retomarmos a epígrafe deste artigo para refletir sobre os sentimentos das homossexuais que foram tratadas como "doentes e pervertidas, párias da sociedade" nas palavras de uma delas. Para Park ${ }^{30}$, a existência de uma atitude sentimental indica que existem motivos para a ação, sobre os quais o indivíduo não tem consciência plena e um controle apenas parcial. Para o autor, todo sentimento tem uma história, mas a pessoa que age movida por esse sentimento pode não estar ciente dessa história. Para o autor, nossos sentimentos se relacionam com os nossos preconceitos, que podem estar associados a qualquer coisa. Os preconceitos estão relacionados também com os tabus, e assim tendem

\footnotetext{
${ }^{26}$ MORROW \& MESSINGER, Sexual orientation and gender expression in social work practice: Working with gay, lesbian, bisexual, and transgender people, p. 85.

27 VELHO, “Observando o familiar", p. 132.

${ }^{28}$ FORTUNA, Urbanidades invisiveis, p. 135-151.

${ }^{29}$ ERIBON, Reflexões sobre a questão gay, p. 30.

${ }^{30}$ PARK, $A$ cidade: sugestões para investigação do comportamento bumano no meio urbano, p. 39.
} 
a manter, além da organização social existente, "distâncias sociais", que, na minha percepção conduzem ao vazio social sobre o qual fala Wirth. ${ }^{31}$

Para entender o trânsito na cidade de Belo Horizonte pelas lésbicas que venho estudando algumas escolhas ainda precisarão ser feitas. Uma possibilidade de entendimento poderia partir da noção de "quase grupos"32, que pressupõem um conjunto de indivíduos em interação e formam uma entidade sem uma estrutura identificável, mas cujos membros possuem determinados interesses ou condutas comuns, que poderão, em algum momento, levá-los a formarem grupos definitivos. ${ }^{33} \mathrm{Ou}$ ainda a possibilidade de entendimento por meio dos circuitos que, de acordo com Magnani ${ }^{34}$, formam uma categoria que descreve o exercício de uma prática ou a oferta de determinado serviço por meio de estabelecimentos, equipamentos e espaços que não mantêm entre si uma relação de contiguidade espacial, mas que são reconhecidos em seu conjunto pelos usuários habituais.

Além de bares e boates voltados à população LGBTQI ${ }^{35}$, era comum às lésbicas mais velhas criarem seus circuitos na noite belorizontina e seus "pedaços", O "pedaço" - lugar dos colegas e dos chegados - é um ponto de referência, impregnado pelo aspecto simbólico. Seus símbolos remetem a gostos, orientações, valores, hábitos de consumo e modos de vida semelhantes. Nos "pedaços" se evoca laços de pertencimento e estabelecimento de fronteiras, neles determinados grupos de frequentadores estabelecem uma rede de relações. ${ }^{36}$ O termo designa aquele espaço intermediário entre o privado (a casa) e o público, onde se desenvolve uma sociabilidade básica, mais ampla que a fundada nos laços familiares, porém mais densa, significativa e estável que as relações formais e individualizadas impostas pela sociedade. ${ }^{37}$

Ao universo gay é comum a utilização de parques e praças como lugares de encontros e lazer. Quanto ao universo lésbico, o aprofundamento durante o trabalho de campo revelará o que a cidade oferecia e o que as lésbicas criaram para a vivência de suas relações afetivosexuais. É dentro das cidades que a maioria das relações se dá. Contudo, muitos planos de cidade não conseguem inscrever o significado das interações das pessoas com os espaços desenhados. É por isso que perguntar sobre se se pode planejar a informalidade da vida urbana tem por trás um não dito que é o convite a desaprender a cidade formal, juntandolhe os significados próprios dos fragmentos não convencionais da urbanidade. ${ }^{38}$

O estudo de mulheres lésbicas organizadas em grupos, a exemplo do que ocorre com as belohorizontinas, pode vir a aprofundar-se, seja pela perspectiva dos "quase grupos" interativos, pelos "circuitos", "pedaços" ou outros cantos que a cidade oferecia. O meu desejo é desvelar para conhecer esse universo de mulheres que compõe uma geração de

\footnotetext{
31 WIRTH, O urbanismo como modo de vida, p. 101.

$32 \mathrm{O}$ conceito de quase grupos, segundo Mayer (Importancia dos "quase grupos" no estudo das sociedades complexas, p.152) pode ser aplicado a qualquer situação na qual atuem grupos não organizados. Esse parece ser o caso de um considerável volume de lésbicas contemporâneas às Confreiras de onde parte o estudo que venho fazendo. Contudo, somente no desenvolver da pesquisa terei condições de avaliar a adequabilidade do termo.

${ }_{33}$ MAYER, Importância dos "quase grupos" no estudo das sociedades complexas, p. 127.

34 MAGNANI, De perto e de dentro: notas para uma etnografia urbana, p. 23.

35 Internacionalmente, a sigla mais utilizada é LGBTI, que engloba as pessoas intersex. Órgãos como a ONU e a Anistia Internacional elegeram esta denominação como um padrão para falar desta parcela da população. Em termos de movimentos sociais, uma denominação que vem ganhando força é LGBTQ ou LGBTQI - incluindo, além da orientação sexual e da diversidade de gênero, a perspectiva teórica e política dos Estudos Queer.

${ }^{36}$ MAGNANI, De perto e de dentro: notas para uma etnografia urbana, p. 21.

${ }^{37}$ MAGNANI, Festa no pedaço: cultura popular e lazer na cidade, p. 116.

${ }^{38}$ FORTUNA, Urbanidades invisiveis, p. 146.
} 
invisíveis, sobre elas, pouco se sabe. Para tanto será necessário captar os elementos intangíveis, espontâneos, irrepetíveis e inscritos na informalidade do cotidiano da vida na cidade.

Apesar de avanços, como no caso do reconhecimento das uniões homoafetivas, no Brasil, há, ainda, longo caminho a ser percorrido na busca da garantia da dignidade humana, no enfrentamento à homofobia e à discriminação. Se atualmente casais de homossexuais adquiriram o direito de se casar, ter filhos e constituir famílias, tal direito chegou tardiamente para a geração de mulheres mais velhas.

É possível que a geração de homossexuais mais jovens se sinta mais à vontade com a própria orientação sexual, tendo em vista o significativo avanço que pode ser observado a partir do reconhecimento legal das uniões constituídas por pessoas de mesmo sexo. Ou, ainda, por exemplo, por meio das políticas públicas, como a criação do Conselho Nacional LGBT, o Programa Brasil Sem Homofobia (2004), o Plano Nacional de Promoção da Cidadania e Direitos Humanos de Lésbicas, Gays, Bissexuais, Travestis e Transexuais (2009), o Programa Nacional de Direitos Humanos - PNDH (1996), o Plano Nacional de Educação em Direitos Humanos (2006), entre outros. Quanto ao legado dessas ações pós-eleições presidenciais no Brasil em 2018, serão necessárias outras pesquisas.

Para Pierre Bourdieu ${ }^{39}$ :

O movimento gay e lésbico coloca, ao mesmo tempo, tacitamente, com sua existência e suas ações simbólicas, e explicitamente, com os discursos e teorias que produz, ou a que dá lugar, um certo número de questões que estão entre as mais importantes das ciências sociais e que, para alguns, são totalmente novas.

Para Marques ${ }^{40}$, as desigualdades sociais têm uma de suas origens na ordem jurídica brasileira e em sua relação com a nossa sociedade, em suas dimensões de tradicionalismo, hierarquia social e preconceito, e tem responsabilidade na produção e reprodução da segregação e das desigualdades no espaço urbano. Não é possível ignorar o impacto disso sobre aqueles que fogem ao padrão heteronormativo. A ordem jurídica brasileira e sua relação com o atraso presente em nossa sociedade estão implicadas na manutenção da ordem vigente.

Segundo Wirth ${ }^{41}$, a população urbana é selecionada e distribuída em locais mais ou menos distintos a depender do trabalho, da renda, das características raciais, étnicas, do status social, dos costumes, hábitos, gostos, preferências e preconceitos. Assim sendo, há que se pensar essa seleção e distribuição à luz dos preconceitos e das limitações vividas pelas homossexuais, seja em decorrência das violências às quais estão expostas seja em decorrência da inadequação que o modelo heteronormativo a elas impõe. Ainda de acordo com Wirth ${ }^{42}$, a vida, em contato estreito e o trabalho em comum, de indivíduos sem laços sentimentais ou emocionais, desenvolve um espírito de concorrência e exploração mútua. Contato físico estreito, frequente, aliado a grande distância social, acentua a reserva de indivíduos não

\footnotetext{
39 BOURDIEU, $A$ dominação masculina, p. 143.

${ }^{40}$ MARQUES, "Elementos conceituais da segregação urbana e da ação do Estado", pp. 22-23.

${ }^{41}$ WIRTH, O urbanismo como modo de vida, p. 105.

42 WIRTH, O urbanismo como modo de vida, p. 104.
} 
ligados entre si e, a não ser que seja compensada por outras oportunidades de reação, dá origem à solidão.

Seguindo a linha de pensamento de Wirth é possível inferir que, contato físico estreito e frequente, aliado a proximidade social acentuaria vínculos de indivíduos ligados entre si e contribuiria para um espírito de fraternidade e ajuda mútua, dando origem à redes de relacionamento e convivência. Este parece ser o caso das "Confreiras" às quais venho me dedicando a estudar e entender. Contudo, para além delas, parece haver outras contemporâneas a elas que tiveram mais dificuldades para compensar as difíceis contingências impostas pela sociedade da época.

\section{Sobre estratégias de convivência, afetos e envelhecimento}

Se é a partir dos processos de interação social que o sentido e o significado nas relações se dão, a forma pela qual a cidade acolhe, ignora ou invisibiliza determinadas pessoas exerce forte impacto sobre suas existências. $\mathrm{O}$ mesmo ocorre com relação às atitudes que tomamos e com as palavras que usamos para nos dirigirmos ou nos referirmos uns aos outros.

As palavras podem designar e estigmatizar sujeitos, perpetuar preconceitos e definir lugares na hierarquia social. Apesar dos tratamentos recebidos - "doentes, pervertidas, párias" as Entendidas trilharam seus caminhos, ainda que de forma velada, e parece ser legítimo reconhecer o legado por elas deixado às mais jovens.

Para as lésbicas mais velhas era impensável, inclusive, a possibilidade de constituir suas famílias dentro das prerrogativas disponíveis aos heterossexuais. Apesar disto construíram vínculos duradouros que parecem manter relação com a construção de suas identidades com desdobramentos tanto para o estilo de vida adotado quando jovens quanto para a qualidade de suas vidas na velhice. Haveria algo a ser aprendido com elas? E aquelas da mesma geração que trilharam outros caminhos aonde chegaram e como estão?

Chance há que, relações de afeto, amizade e solidariedade somadas à presença ou a ausência de potentes vínculos no campo social, afetivo, econômico-financeiro, em menor ou maior grau - podem determinar trajetórias diferentes, mas parece ser elemento fundamental para a qualidade da vida na velhice.

Partindo desse cenário, poderíamos nos perguntar quais são os elementos fundamentais à construção de potentes redes de sociabilidade, amizade, apoio e solidariedade erigidas por alguns sujeitos marginalizados, como parece ser o caso das mulheres focalizadas neste artigo.

Se o passado se impõe ao presente, faz-se necessário nos indagar como as vidas das Etendidas mais velhas foram impactadas a partir da trajetória que tiveram na cidade de Belo Horizonte, e a isto me dedicarei: histórias marginais de vidas que importam. 


\section{Referências bibliográficas}

BENEDICT, Burton. "Sociological Characteristics of Small Territories and their Implications for Economic Development". In: BANTON, Michael (org.). The Social Anthropology of Complex Societies. London: Tavistock (A.S.A. Monographs 4), 1968.

BENJAMIN, Walter. Passagens. (org.) Willi Bolle. Belo Horizonte/São Paulo: UFMG/Imprensa Oficial do Estado de São Paulo, 2009.

BOURDIEU, Pierre. A dominação masculina. Rio de Janeiro: Bertrand Brasil, 1998.

DE SOUZA, Janice Aparecida. Estratégias de Escolarização de Homossexuais com Sucesso Acadêmico. Dissertação (Mestrado em Educação) Universidade Federal de Minas Gerais, Belo Horizonte, 2013.

DIAS, Maria Berenice. Rumo a um novo direito. In: DIAS, Maria Berenice (org). Diversidade Sexual e Direito Homoafetivo. São Paulo: Editora Revista dos Tribunais, 2011, pp. 249-263.

ERIBON, Didier. Reflexões sobre a questão gay. Rio de Janeiro: Companhia de Freud, 2008.

FORTUNA, Carlos. Urbanidades invisíveis. In: Tempo Social. Revista de sociologia da USP, v. 31, n. ${ }^{\circ}$ 1, pp. 135-151, abr. 2019.

GUIMARÃES, Carmen. O homossexual visto por entendidos. Rio de Janeiro: Editora Garamond, 2004.

JÚNIOR, Enézio de Deus Silva. Homofobia e Violência Doméstica. In: DIAS, Maria Berenice (org). Diversidade Sexual e Direito Homoafetivo. São Paulo: Editora Revista dos Tribunais, 2011, pp. 495-510

MAGNANI, José Guilherme. Festa no pedaço: cultura popular e laz̧er na cidade. $1^{\text {a }}$ Ed. São Paulo: Brasiliense, 1998.

. "De perto e de dentro: notas para uma etnografia urbana". In: Revista Brasileira de

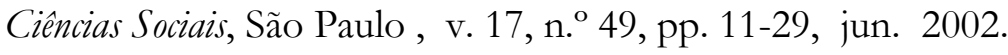

MARQUES, E. "Elementos conceituais da segregação urbana e da ação do Estado". In: MARQUES, E. e TORRES, H. (org.). São Paulo: segregação, pobreza urbana e desigualdade social. São Paulo: Senac, 2005.

MAYER, Adrian C. "A Importância dos "quase grupos" no estudo das sociedades complexas”. In: C. FELDMAN-BIANCO, Bela (org.). Antropologia das sociedades contemporâneas. São Paulo: Global Universitária, 1987.

MERLEAU-PONTY, Maurice. "De Mauss a Claude Lévi-Strauss". In: Textos Selecionados. São Paulo: Abril Cultural (Coleção Os Pensadores), 1984. 
MORROW, D. F., \& MESSINGER, L. (Eds.). Sexual orientation and gender expression in social work practice: Working with gay, lesbian, bisexual, and transgender people. New York: Columbia University Press, 2006.

L. MOORE, H. "Fantasias de poder e fantasias de identidade: gênero, raça e violência". In: Cadernos Pagu, n. 14, pp. 13-44, 2000.

NAVARRO-SWAIN, T. O que é lesbianismo. São Paulo: Brasiliense, 2004.

PARK, Robert E. "A cidade: sugestões para investigação do comportamento humano no meio urbano". In: VELHO, O. (org.). O fenômeno urbano. Rio de Janeiro: Zahar, 1973.

TEIXEIRA, Alexandre Eustáquio. Territórios homoeróticos em Belo Horizonte: um estudo sobre interações sociais nos espaços urbanos. 2003. Dissertação (Mestrado em Ciências Sociais) Pontifícia Universidade Católica de Mina Gerais, Belo Horizonte, 2003.

VELHO, Gilberto. “Observando o familiar”. In: Individualismo e cultura. Rio de Janeiro: Zahar, 1987.

WIRTH, L. "O urbanismo como modo de vida". In: VELHO, Otávio (org.), O Fenômeno Urbano. Trad. de Marina Côrrea Treuherz. Rio de Janeiro: Ed. Jorge Zahar, 1979, pp. 90 113. 